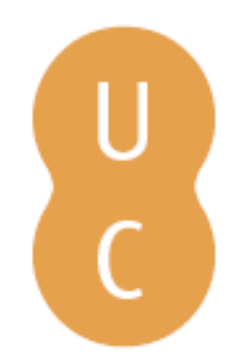

\title{
pompalina
}

\section{Animalizar lo masculino: penteo en Bacantes de Eurípides}

Autor(es): $\quad$ Rodríguez Cidre, Elsa

Publicado por: Centro de Estudos Clássicos e Humanísticos da Universidade de

URL

persistente: URI:http://hdl.handle.net/10316.2/30284

DOI: $\quad$ DOI:http://dx.doi.org/10.14195/978-989-721-038-9_54

Accessed : $\quad$ 26-Apr-2023 03:04:37

A navegação consulta e descarregamento dos títulos inseridos nas Bibliotecas Digitais UC Digitalis, UC Pombalina e UC Impactum, pressupõem a aceitação plena e sem reservas dos Termos e Condições de Uso destas Bibliotecas Digitais, disponíveis em https://digitalis.uc.pt/pt-pt/termos.

Conforme exposto nos referidos Termos e Condições de Uso, o descarregamento de títulos de acesso restrito requer uma licença válida de autorização devendo o utilizador aceder ao(s) documento(s) a partir de um endereço de IP da instituição detentora da supramencionada licença.

Ao utilizador é apenas permitido o descarregamento para uso pessoal, pelo que o emprego do(s) título(s) descarregado(s) para outro fim, designadamente comercial, carece de autorização do respetivo autor ou editor da obra.

Na medida em que todas as obras da UC Digitalis se encontram protegidas pelo Código do Direito de Autor e Direitos Conexos e demais legislação aplicável, toda a cópia, parcial ou total, deste documento, nos casos em que é legalmente admitida, deverá conter ou fazer-se acompanhar por este aviso.

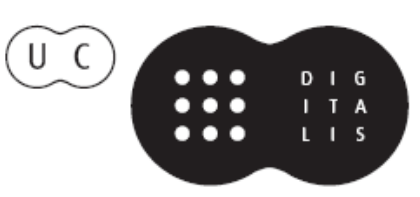




\section{De ayer a hoy}

\section{Influencias clásicas en la literatura}

\section{Aurora López, Andrés Pociña, Maria de Fátima Silva (coords.)}




\title{
Animalizar lo masculino: PENTEO EN BACANTES DE EURÍPIDES ${ }^{\mathrm{I}}$
}

\author{
Elsa Rodríguez Cidre \\ Universidad de Buenos Aires - Conicet
}

\begin{abstract}
En la sociedad ateniense se detecta continuamente la referencia al mundo animal salvaje como el lenguaje de un mundo prepolítico y por ello conforma un mecanismo de construcción en el imaginario de la alteridad. Esto es visible en el diseño de las mujeres trágicas frecuentemente animalizadas. Sin embargo, también hallamos personajes masculinos en este registro. Intentamos relevar las referencias corporales de Penteo en Bacantes para calibrar sus cargas sémicas y su función en la estructura de la obra. La animalización presenta una riqueza que invita a su focalización en la tragedia: Eurípides despliega en Bacantes un uso muy importante, con diversidad de mecanismos y de grados de intensidad dramática.
\end{abstract}

Los personajes de la tragedia griega suelen ser objeto de un proceso de animalización. Este habitual mecanismo de construcción de la alteridad se detecta especialmente en los personajes femeninos de Eurípides (a menudo también extranjeras y esclavas, una suerte de alteridad exponencial) pero no es un coto exclusivo de las mujeres sino que es posible también hallar a personajes masculinos en este registro. Nuestro objetivo en esta ponencia es relevar un caso paradigmático, la animalización de Penteo en Bacantes de Eurípides y analizar las referencias a su cuerpo (íntegro primero y descuartizado después) de modo de calibrar sus cargas sémicas y su función en la estructura general de la obra.

La animalización de Penteo se estructura básicamente en torno de su sparagmós o descuartizamiento que ejecutan, llevadas por la locura báquica, las ménades de Dioniso conducidas por Ágave, la madre del protagonista ${ }^{2}$. Es esta escena (vv. 1088 y ss.) la que dispara una serie de animalizaciones generales y específicas sobre el cuerpo del joven rey de Tebas, o más bien, sobre lo que restará de él, su cabeza portada a palacio como trofeo por su madre filicida, agente inconsciente de la venganza del dios sobre aquel que le negara reconocimiento y culto.

El sparagmós de Penteo no se produce sin una preparación del espectador. En efecto, la trama presenta previamente, en los vv. 731 y ss., una escena de

\footnotetext{
${ }^{1}$ La presente ponencia se enmarca en el proyecto PICT 2008-0206 (ANPCyT). La edición base es la de Diggle.

${ }^{2}$ Para un detalle de la iconografía del sparagmós, cf. Hernández de la Fuente (2001: 89-91).
} 
fuerte intensidad dramática en la cual las ménades proceden en el bosque al descuartizamiento de unas reses munidas solo con la fuerza de sus manos y del influjo báquico. Esta escena, que destila sangre y prolifera en la descripción de colgajos de carne, se conjuga con otro elemento dionisíaco, la omophagía. Este consumo de carne cruda reverbera en el auditorio que ha escuchado de boca del coro cómo Dioniso se da al gusto de la carne cruda del cabrito que captura en el bosque (vv. 135-140).

Al mismo tiempo, otro descuartizamiento funciona en esta obra como un trasfondo mítico muy cercano a los protagonistas. Se trata del de Acteón, cuyo cuerpo fuera despedazado por su propia jauría, en el mismo lugar en el que acontecerá el de Penteo, quien a la sazón es su primo ${ }^{3}$. La referencia al sparagmós de Acteón se produce antes y después del de Penteo. En los vv. 337-342, Cadmo intenta poner en razones a su nieto recordándole el funesto destino de su primo, quien en la versión de Cadmo (que difiere del mito tradicional) sufre su muerte por una ofensa directa contra una divinidad:

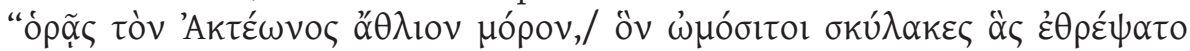

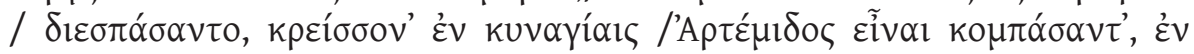

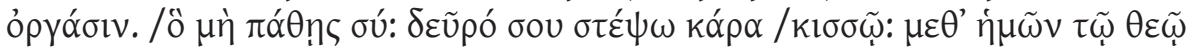

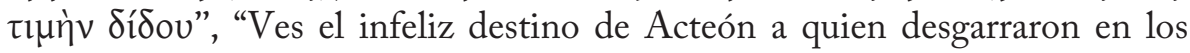
bosques las perras comedoras de carne cruda que él alimentó, por haberse jactado de ser superior a Ártemis en las cacerías. No sufras tú esto: aquí coronaré tu cabeza con hiedra; honra con nosotros al dios". El desafío de Acteón a Ártemis homologa el de Penteo a Dioniso, lo cual sumado al hecho de que Eurípides feminiza a la jauría, hace de la muerte de Acteón una anticipación de la de su primo. Recordemos que Ágave (vv. 731-733) y el coro (v. 977-981) relacionan a las "perras" con las ménades. Rescatemos también la referencia a la carne cruda. Por último, cuando al final de la obra Ágave regrese del influjo báquico y tome conciencia de su filicidio, sabrá de boca de Cadmo que Penteo

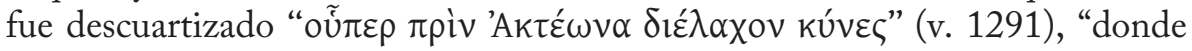
antes las perras se repartieron a Acteón"4.

Más allá de la sugerente relación entre Penteo y Acteón, el mero paralelismo entre el descuartizamiento de las reses y el sparagmós del rey tebano ubica al personaje de lleno en el plano animal. Antes de esta escena, es posible relevar

${ }^{3}$ La madre de Acteón se encuentra entre las ménades, como se ve en los vv. 228-230 y $1227-1232$.

${ }^{4}$ Tangencialmente podríamos incluir otro sparagmós en el horizonte, aquel que sufriera Orfeo (mentado en los vv. 561-563) a manos de las ménades por rehusarse al eros. Este personaje

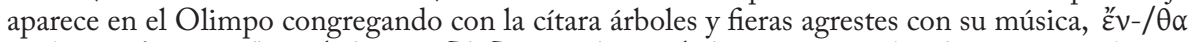

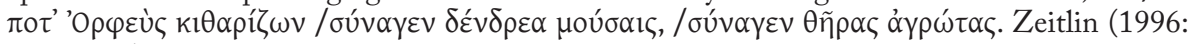
283 n.120) señala que Orfeo rehúsa el eros -o por lo menos el eros heterosexual- después de su pérdida de Eurídice y es despedazado por ménades (así lo presenta Virgilio en Geórgicas 4.516522 y Ovidio en Metamorfosis X.78-83, 11.7). 
referencias a una animalización del rey tebano pero todas se sitúan en un plano más connotativo que denotativo. Así el adivino Tiresias (v. 361) se referirá a

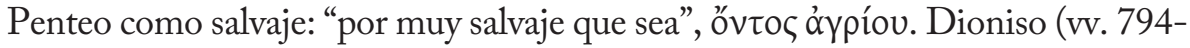
795) califica la conducta de su rival también en clave animal al afirmar que el tebano "cocea" ${ }^{5}$. Asimismo, también en boca del dios se dice que Penteo cae en la red, $\dot{\varepsilon} \varsigma \beta \beta^{\prime} \lambda o v$, siendo $\beta o ́ \lambda o \varsigma$ la red que se emplea para atrapar peces ${ }^{6}$. Por último, una referencia de Dioniso puede leerse también en este sentido cuando el dios explica a las bacantes que prepara el adorno de Penteo con el que partirá

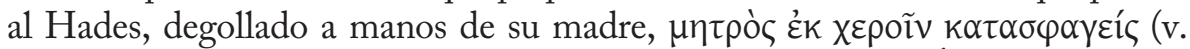
858): el degollamiento (mención equívoca por cierto ya que Ágave en sentido estricto no degollará a su hijo) plantea una valencia animal al situar la referencia en el mundo simbólico del sacrificio ${ }^{7}$. Como vemos, se trata en todos los casos de formas indirectas y contextuales de animalización de Penteo.

Si nos ubicamos en el desarrollo del descuartizamiento, la animalización comienza a tornarse directa. En los vv. 989-992 Ágave se pregunta acerca de quién ha dado a luz al espía de las montaraces cadmeas y su respuesta

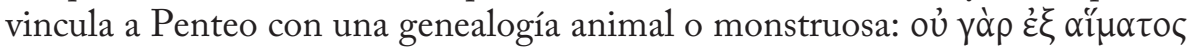

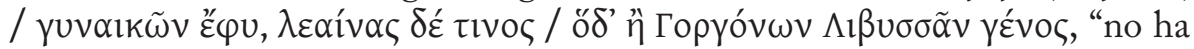
nacido de sangre de mujeres sino de alguna leona o del linaje de las Gorgonas de Libia" ${ }^{\circ}$. Ya a punto de concretarse el sparagmós, el mensajero cita las palabras de Ágave donde anima a las ménades tebanas a rodear en círculo el tronco del

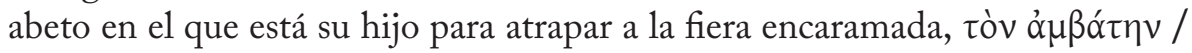
$\theta \tilde{\eta} \rho^{\prime}$ (vv. 1107-1108) ${ }^{9}$. Penteo ha devenido ahora en fiera, pero como señala Dodds (1960: 216), se trata de una bestia que también actúa como humano al

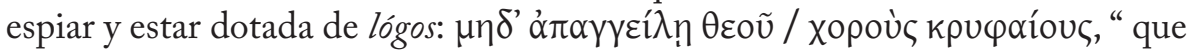
no divulgue las secretas danzas del dios" (vv. 1108-1109)

${ }^{5}$ Penteo amenaza a Dioniso y este le responde que él habría sacrificado al dios antes que

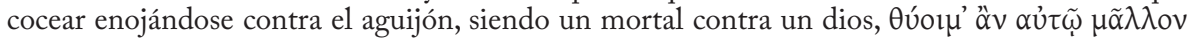

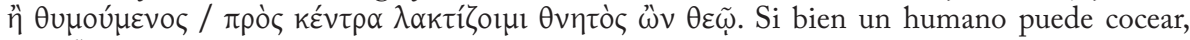
$\lambda \alpha \kappa \tau i \zeta \omega$, los ejemplos son abundantes respecto de animales y es sugerente la idea del rey dando patadas contra un dios y alejándose de su condición humana. Esta metáfora aparece en fr. 604, A.A. 1624, A.PV323, Pi. P. 2.94, cf. Seaford (1996: 212). Cf. también Dodds (1960: 180). Roux (1972: 504) se detiene en el uso de la voz media ya que podemos interpretar que Penteo se arroja a sí mismo en la red después de haber rehusado todos los medios de salvación que le fueron ofrecidos. Para esta autora el v. 847 funciona como un veredicto en tanto es la primera mención en la obra de un castigo de Penteo.

${ }^{6}$ Para la metáfora, cf. E.Rh. 730, E. Alexandros fr. 43 y Hdt. I.62.4

${ }^{7}$ Para un estudio de la degollación en clave animal cf. Rodríguez Cidre (2010: 195-226).

${ }^{8}$ Bollack (2005: 82) señala que el enemigo no puede ser más que animal; es la fase monstruosa de la animalidad. Para un estudio de lo monstruoso en el personaje de Penteo, cf. Rodríguez Cidre (2011b).

${ }^{9}$ Para el valor ritual de este verso, cf. Roux (1972: 580-581).

${ }^{10}$ Ver también Seaford (1996: 237). 
A partir del v. 1125 empieza en sentido estricto el sparagmós del rey. En la descripción de la dispersión de las partes del cuerpo el mensajero nos relata que Ágave ha tomado la cabeza y después de hincarla en la punta de su tirso la lleva como si fuera la de un león salvaje ỏ $\rho \varepsilon \sigma \tau$ ́́ (vv. 1141-1142)11. Es la primera vez que nos encontramos con un animal concreto respecto del proceso de animalización de Penteo, aunque en un punto ya viene anunciado con la remisión previa a la sangre de leona ${ }^{12}$. A partir de aquí esta imagen leonina será recurrente. El león aparece como un trofeo de caza codiciado y es así como lo ve Ágave: $\chi \omega \rho \varepsilon \tilde{i} \delta \dot{\varepsilon} \theta \eta ́ p \alpha \underline{~} \delta v \sigma \pi o ́ \tau \mu \omega$

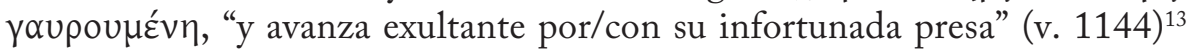
La referencia a este animal está, entonces, ligada fundamentalmente al campo semántico de la caza, en la cual brilla la reina "acompañada" siempre por el dios que la desquicia ${ }^{14}$. Respecto del acto de hincar la cabeza en el tirso, Dodds (1960: 218) sostiene que representa un toque de horror adicional, que bien podría ser otra innovación de Eurípides: en los vasos, Ágave aparece llevando la cabeza por el pelo tanto antes como después de la fecha de Bacantes y cabe notar que en el v. 1277 la madre parece tomar la cabeza de su hijo en sus manos. Roux (1972: 584-585) destaca el carácter escandaloso para los griegos de esta práctica, típicamente bárbara, que en este caso tiene la función de señalar que el castigo del hijo ya está cumplido mientras que el de la madre recién comienza ${ }^{15}$.

En el v. 1168 Ágave entra en escena con el tirso coronado con la

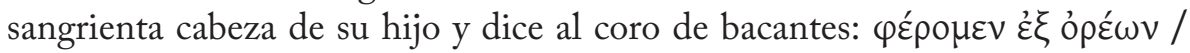

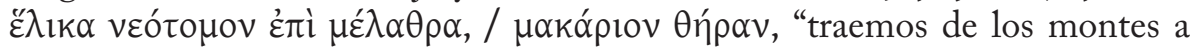
casa zarcillos de hiedra/vid recién cortados, una bienaventurada presa ${ }^{16 ”}$ (vv.

${ }^{11}$ Musurillo (1966: 62) considera que esta escena y la de la descripción de la muerte de la hija de Creonte en Medea conforman "the most nauseating descriptions in all of Greek literature".

${ }^{12}$ Cf. Seisdedos (1985: 289).

${ }^{13}$ Para Seaford (1996: 239) la separación de Ágave de las otras ménades puede relacionarse con el rol de líder en la matanza $(1114,1183,1239)$ y su función dramática permite su entrada patética en soledad.

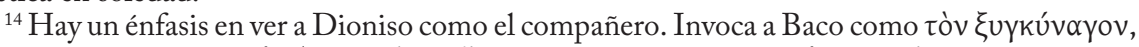

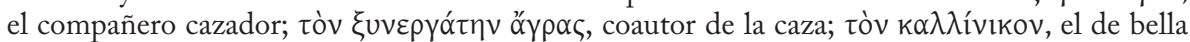
victoria (vv. 1145-1147). Para Dodds (1960: 219) los tres epítetos son paralelos e independientes representando respectivamente la caza, la matanza y el triunfo. Para Roux (1972: 584-585) las tres invocaciones de Ágave recuerdan los tres momentos del drama: la caza, la captura,

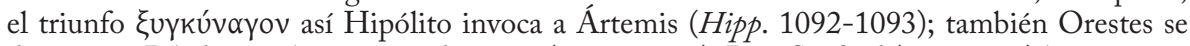
dirige así a Pílades en el momento de morir (IT709-710). Para Seaford (1996: 239) la secuencia balanceada de las apelaciones en parataxis es característica de frase ritual como el encomio, cf. A.A. 896-901, P1. Smp. 197de, Gorg. B60-K.

${ }_{15}$ Así Jerjes hace cortar la cabeza de Leónidas y ordena clavarla en una estaca (Hdt., VII, 238). En Il. XVIII, 177, se dice que la intención de Héctor era clavar la cabeza de Patroclo sobre una estaca de la empalizada.

${ }_{16}$ Seaford (1996: 242-243) señala que es la primera de las apariciones de makários (1180, 
1169-1171). Aquí los elementos animales y vegetales se entrecruzan pues Ágave identifica el cabello enrulado y la barba de su hijo con las hojas de vid de la punta del tirso ${ }^{17}$. Esta asimilación nos remite al delirio de la madre pero, tratándose de una bacante filicida, nos reenvía a la historia de Licurgo, quien bajo el influjo de la locura dionisíaca, confunde a su hijo con un vástago de viña y lo $\operatorname{corta}^{18}$. El dios, vemos, no se restringe al mundo animal para montar sus venganzas.

Las referencias a la caza son en esta sección pregnantes. Ágave explica al

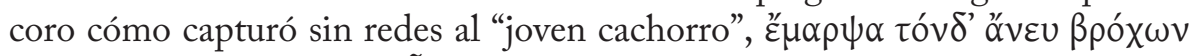

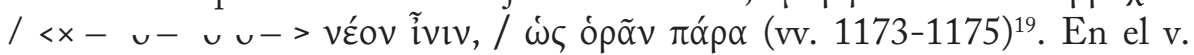
1179 la hija de Cadmo relata el hecho de haber sido la primera en herirlo ${ }^{20}$ y en los vv. 1182-1184 vuelve a referirse a su hijo como fiera y agrega una

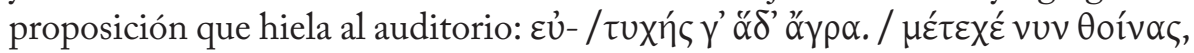
"dichosa, esta cacería; participa ahora del festín". El coro responde con una nueva pregunta que señala los alcances de su involucramiento en la locura de

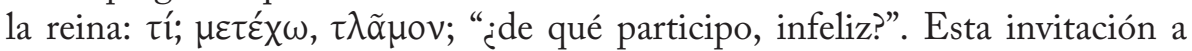
un festín, presumiblemente con los restos de Penteo como plato principal, es demasiado para el coro, como señala Dodds (1960: 224), y es por eso que su actitud de aprobación forzada se rompe ${ }^{21}$. Devendría antropofagia la omophagía dionisíaca que evoca también el tema mítico de que las ménades comen a sus propios hijos ${ }^{22}$.

Las referencias a la caza seguirán multiplicándose y se instalará claramentela tríada de elementos complementarios Dioniso conductor/Ménades cazadoras/ Penteo fiera como se ve en los vv. 1189-92 que recuerdan inmediatamente la descripción realizada por el coro de la captura y consumo del cervatillo por $\mathrm{Baco}^{23}$. La valencia leonina regresa en los vv. 1195-1196 mediante el hápax

1232,1242-3,1258), palabra que en contexto puede evocar (irónicamente) la felicidad traída por la iniciación mística $(72-4,902-5)$ así como la caza en el rito del pasaje a la adultez.

${ }^{17}$ Cf. Dodds (1960: 223).

${ }^{18} \mathrm{Cf}$. Apollod., 3.5.I. Recordemos que estas líneas fueron recitadas en el 53 a.C. en el medio de un aplauso general en la corte por un actor vestido de Ágave que llevaba una cabeza humana real, la de Craso, el general romano, cf. Plu., Crass., 33.

${ }^{19}$ Para el prestigio de la caza sin redes ver Pi. N.3.51-2, P1. Lg. 824a; cf. Seaford (1996: 243). Diggle y Seaford mantienen la laguna textual. Dodds, Roux, Di Benedetto, Torrano y Tovar

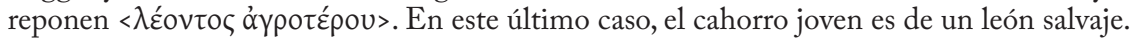

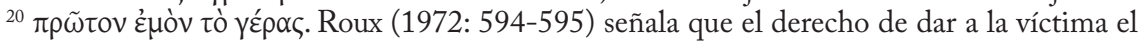
primer golpe es el privilegio reservado al jefe del tíasos, al éxarkhos; la madre de Penteo tiene ese rol a lo largo de toda la pieza $(689,731,982,1114,1125)$.

${ }^{21}$ Cf. Opp., C. 4.304, donde Penteo es transformado en toro y las ménades en panteras que despedazan y comen el toro.

${ }_{22}$ Plut. Moralia, 299e, Apollod., 3.5.2). Cf. Seaford (1996: 244-245). Cf. también Andrade (2003: 95). Roux (1972: 596) señala que Eurípides con mal gusto hace que Ágave presente un pedazo de carne para que las bacantes puedan comprobar la frescura y acepten.

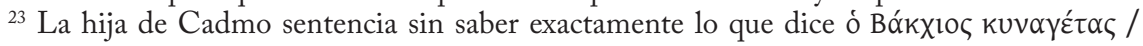


$\lambda \varepsilon \operatorname{lov}_{\tau} \varphi \varphi \tilde{\alpha}$ que describe la naturaleza de la presa, calificada de extraordinaria por Ágave y las bacantes en el marco de un despliegue de altivez en torno de la modalidad (con las manos) y resultados (cabeza de león como signo de victoria)

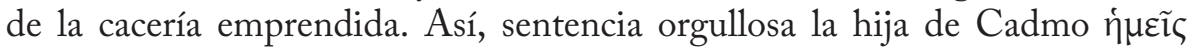

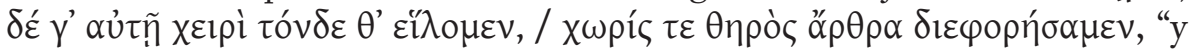
nosotras por propia mano capturamos a éste y descuartizamos los miembros de esta fiera" ( vv. 1209-1210) para pedir a continuación la presencia de su hijo para que cuelgue "en los triglifos esta cabeza de león que presento después de

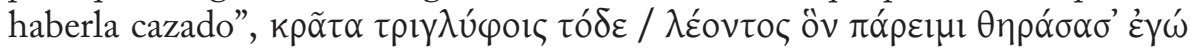
(vv. 1214-1215).

Ahora bien, no es la caza el único marco de referencia para la animalización de Penteo. En efecto, se cruza aquí otro mundo simbólico, el del sacrificio, que explica otro tipo de identificaciones animales del rey tebano. En su delirio Ágave también ve en la cabeza que porta a un joven cachorro, véoৎ ó $\mu o ́ \sigma \chi \circ \varsigma$

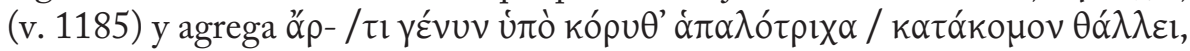
"recién florece su mejilla bajo la mata de suave cabellera que cae" (vv. 1185-

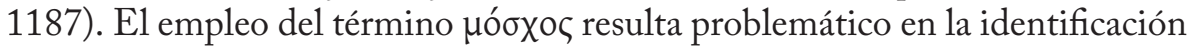
precisa del animal referido. Para las ediciones comentadas consultadas se trata de un ternero: la vellosidad bajo las mejillas de Penteo justifica mejor que una barba en el mentón la comparación con un bovino ${ }^{24}$. Seaford (1996: 244-245) marca cómo la percepción enloquecida de Ágave va variando: Penteo parece primero un león (vv. 1142, 1196, 1215, 1278), luego una hiedra (v. 1170) y ahora un toro (móskhos puede significar eso como por ejemplo en los vv. 678 y 736). Lo cierto es que si la caza requiere de animales salvajes como el león, el sacrificio (1024-1152n.) en cambio atañe a aquellos más en contacto con el mundo humano y social, vale decir, del ganado. Como ternero, Penteo puede adquirir un aspecto más humano -como un joven con su primera barba ${ }^{25}$. Su juventud evoca tanto la edad deseada de la víctima sacrificial como el lazo maternal $(1174,969,974)$. El coro en el v. 1188 mantiene la misma imagen

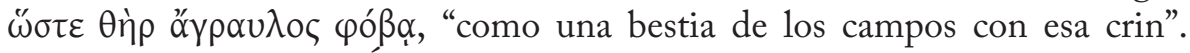
Recordemos el rol de Ágave como bieréa, sacerdotisa del sacrificio en el v. $1114^{26}$.

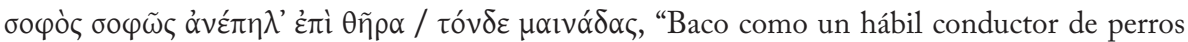
hábilmente incitó a las ménades contra esta fiera” (vv. 1189-1191) y el coro cierra ó үờ óv ớ

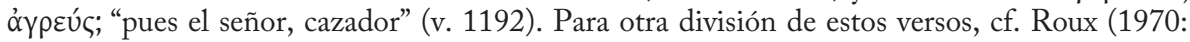
199) y Roux (1972: 595-596). El término ợpeúc es usado también para Apolo y Poseidón. Roux (1972: 596) destaca que el hecho de que esté precedida por ơv $\alpha \xi$, podría evocar a Zagreus, una divinidad cretense identificada con Dioniso desde tiempos helenísticos y quizás aún en tiempos de Eurípides (Cret. fr. 472, 11-15). Cf. también Dodds (1960: 224).

${ }^{24}$ Cf. Roux (1972: 596).

${ }^{25}$ Cf. X. Smp. 4.23

${ }^{26}$ Cf. Rodríguez Cidre (2011ª). 
De todos modos, caza y sacrificio muestran elementos en común, dejando de lado el obvio de la víctima animal (o animalizada como es el caso aquí). Como interpreta Seaford (1996: 237) la violencia contenida del sacrificio se transforma en la violencia desenfrenada de la caza y remarca que tanto uno como otra son seguidas normalmente de un festín común ${ }^{27}$. Asimismo, Dodds (1960: 226-227) recuerda que las cabezas de las víctimas sacrificiales eran a veces similarmente exhibidas sobre picas ${ }^{28}$.

Este diálogo entre caza y sacrificio lo vemos nuevamente en el último núcleo de la tragedia, central para nuestra cuestión puesto que el anagnorismós de Ágave, conducido magistralmente por su padre, clausura el proceso de animalización de Penteo, quien debe volver a ser humano para que la venganza sea completa. En efecto, mientras que la reina se mantiene en el registro de la gloria cazadora apelando a sus "proezas", incluso cuando Cadmo ingresa a escena con sus servidores acarreando los restos de Penteo (diferentes partes de un cuerpo descuartizado), su padre se posiciona en cambio en el ámbito del

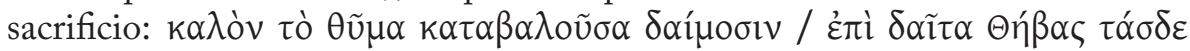
$\kappa \alpha \dot{\mu} \mu \grave{\varepsilon} \pi \alpha \rho \alpha \kappa \alpha \lambda \varepsilon \tilde{\imath} \varsigma$, "tras derribar ${ }^{29}$ la hermosa víctima de sacrificio llamas a un banquete a Tebas y a mî" (vv. 1246-1247). La cazadora, quien ya ha bajado de su tirso la cabeza (cf. 1141 y 1200) que yace en sus brazos ${ }^{30}$, responde no solo reafirmando el elemento cinegético, sino que a partir de él, como plantea Thumiger (2007: 139), viola triplemente su estatuto de madre: no reconoce a su hijo, es la causante de su muerte e incluso lo degrada en su virilidad como

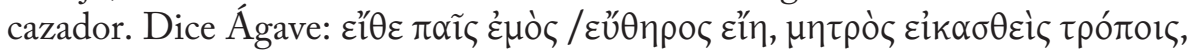

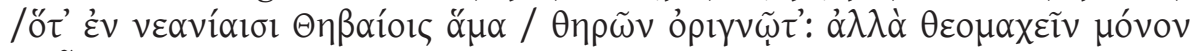

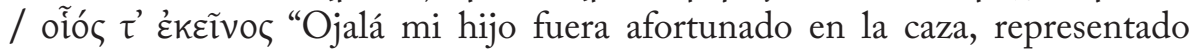
por las maneras de su madre cuando con los jóvenes tebanos conjuntamente persigue las fieras; pero aquél solo es capaz de luchar contra los dioses" (vv. 1252-1256). Remarquemos que el uso del término عü $\eta\rceil \rho \circ$ resulta irónico pues su significado de "buen cazador" viene dado desde una etimología que lo sindicaba como "buena fiera" 31 .

La última animalización de Penteo se da precisamente en los versos en los que Cadmo empieza a sacar a su hija del delirio báquico (vv. 1277-1284). Cuando al preguntarle de quién es el rostro que tiene en sus brazos ${ }^{32}$, ella

\footnotetext{
${ }^{27}$ Cf. Seaford (1996: 244-245).

${ }^{28}$ Recordemos cómo el mismo Eurípides en IT, 74 y ss. nos presenta a los salvajes tauros dedicando las calaveras humanas.

${ }^{29}$ Roux (1972: 606-607) señala que $\kappa \alpha \tau \alpha \beta \alpha \lambda$ oṽ $\sigma \alpha$ designa el golpe dado a una víctima de sacrificio (E.Or. 1603).

${ }^{30}$ Nótese cómo se cumple la predicción realizada por el dios en los vv. 968-969, cf. Roux (1972: 606-607).

${ }^{31}$ Cf. Andrade (2003: 96).

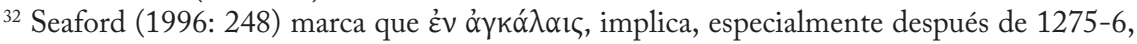




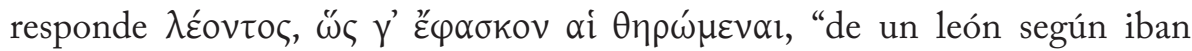
diciendo las cazadoras”. El león sigue presente pero comienza a desdibujarse pues ya no es ella quien afirma que es un león ni se incluye taxativamente en el conjunto de cazadoras. Roux (1972: 610-611) rescata el uso del término

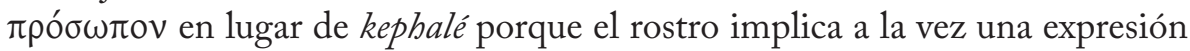
humana y una identidad. Esto nos interesa en función de la re-humanización de Penteo aunque cabe notar que esta referencia también da pie a una larga discusión respecto de la performance de la obra. En efecto, la palabra contiene también la indicación de un juego de escena: en ese momento Ágave tendría la cabeza por los cabellos y no podría ver la mirada que Cadmo la invita a examinar. Pero la naturaleza de esta cefaloforía es motivo de discusión entre los críticos pues unos consideran que se trataba de una cabeza de utilería, otros que Penteo viene representado por la peluca que Dioniso ajustara a su cabeza en la escena del travestimiento y, finalmente, la mayoría de los especialistas sostiene que $\pi \rho o ́ \sigma \omega \pi o v$, aquí como en el conjunto del drama antiguo hasta el s. IV, refiere a la máscara del actor. Ágave portaría la máscara con la que los espectadores reconocían a Penteo, una máscara que en el teatro antiguo se hacía con rostro y cabellos. En este sentido, es significativo que se trate del mismo actor el que interpreta a Ágave y a Penteo (y dado que la última imagen de Penteo para la audiencia era la de un hombre travestido, la única diferencia con Ágave radica precisamente en el cambio de máscara) ${ }^{33}$. Sea lo que fuere, llevada por la serie de preguntas que le formula Cadmo, la infeliz reconocerá que no cree que se trate de una cabeza de león sino la de su hijo Penteo $^{34}$. Una vez que la madre humaniza la cabeza de su hijo, éste no volverá a ser animalizado.

Para concluir señalemos el rol central que cumple la corporeidad de Penteo en el desarrollo general de la obra y en particular en lo que concierne al registro de la animalización. Como señala Drew Griffith (1998: 230-231, 249), deberíamos esperar en el drama un uso importante de órganos corporales como objetos significantes, desde el momento en que el cuerpo es ingresado

un niño en los brazos de su madre; cf. 969, 699-70, E.Cyc. 142, E.IT 834, E.Or. 464, E.Ion 280,1375 , etc.

${ }^{33}$ Cf. Foley (2003: 365-366), Rehm (2002: 209-210), Marshall (1999: 193), Segal (1997: 215, 239, 260-261), Wiles (1999: 174, 225), Taplin, O. (2005 [1978]: 73-74), Seaford (1996: 248). Para un detalle de la iconografía de la cefaloforía, cf. Hernández de la Fuente (2001:91-94).

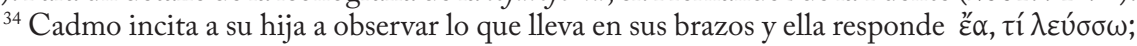

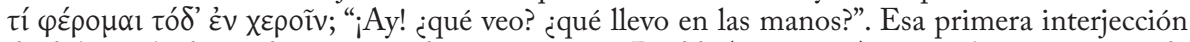
de dolor es la deixis de un inicio de anagnorismós. Dodds (1960: 231) rescata la importancia de la voz media en $\varphi \varepsilon ́ p o \mu \alpha \mathrm{l}$ : Ágave lleva la cabeza como su premio y como su contaminación (cf. fr. I ídion élabon es khéras mýsos). Su padre vuelve a invitarla a examinar la situación y entonces admite ver el más grande de los dolores (nótese aquí la ausencia de juego de palabras entre el término que usa y el nombre de Penteo). 
en escena de una manera en que no aparece en la épica ni en la lírica en tanto instrumento del actor y, desde esta perspectiva, la cabeza de Penteo sólo es comparable "in terms of plurisignation" con los pechos de Clitemnestra en Coéforas (vv. 896-897).

El cadáver de Penteo es sometido a una doble deshumanización. Por un lado, la serie de equívocos que lo convierten en fiera, león, hiedra o ternero. Por otro, su descuartizamiento, desarticulación que convierte un resto humano en un conjunto de colgajos, pasibles incluso de ser considerados plato de un festín. Solo la cabeza, portadora de un rostro que mantiene una ligazón con la identidad perdida, podrá convertirse en el instrumento que rehumanice a Penteo tras haber sido el centro de los mecanismos de animalización experimentados en la obra. 


\section{BibLIOgRAFÍA}

Andrade, N. (2003), Euripides. Bacantes, Buenos Aires, Biblos.

Di Benedetto, V. (1982) , Euripide. Medea-Troiane-Baccanti, Milán, Rizzoli.

Diggle, J. (1994), Euripidis Fabulae III, Oxford, University Press.

Dodds, E. R. (1960), Euripidis Bacchae, Oxford, University Press.

Roux, J. (1972), Euripide. Les Bacchantes, Paris, Les Belles Lettres.

Seaford, R. (1996), Euripides: Bacchae, Warminster, Aris \& Phillips.

Torrano, J. (1995), Eurípides. Bacas, San Pablo, Ed. Hucitec.

Tovar, A. (1982), Tragedias. Las Bacantes. Hécuba, Madrid: CSIC.

Bollack, J. (2005), Dionisos et la tragédie. Commentaire des Bacchantes d'Euripide, Paris, Bayard.

Burian, P. (1997), "Myth into Muthos: the shaping of tragic plot", en Easterling, P. E., The Cambridge Companion to Greek Tragedy, Cambridge, University Press, 178-208.

Drew Griffith, R. (1998), “Corporality in the Ancient Greek Theatre”, Phoenix 52 3-4, 230-256.

Foley, H. P. (2003), “The Masque of Dionysus”, en Mossman, J. (Ed.), Oxford Reading in Classical Studies. Euripides, 342-368.

Hernández de la Fuente, D. A. (2001), "Sparagmos y cefaloforía en Las Bacantes y Las Dionisiacas: El mito de Penteo en Eurípides y Nono", CFC 11, 79-100.

Marshall, C.W. (1999), "Some Fifth-Century Masking Conventions “, G\&R 46 2, 188-202.

Mossman, J. (1995), Wild Justice. A study of Euripides' Hecuba, Oxford, Clarendon Press.

Musurillo, H. (1966), “Euripides'Medea: a reconsideration”, AJPh 137, 52-74.

Rehm, R. (2002), “The Bacchae: The Theatrical Body”, en The Play of Space. Spatial Transformation in Greek Tragedy, Princeton: University Press, 200-214.

Rodríguez Cidre, E. (2010), Cautivas Troyanas. El mundo femenino fragmentado en las tragedias de Eurípides, Córdoba, Ordia Prima.

Rodríguez Cidre, E. (2011a), "Sacrificar en Bacantes: Ágave y el colectivo de mujeres", Actas de las V Jornadas sobre el Mundo Clásico: "Saber y poder. Claves de la constitución de la identidad" (octubre de 2010), Universidad de Morón, (en prensa). 
Rodríguez Cidre, E. (2011b), "Ser hijo de Equión: lo monstruoso en Bacantes de Eurípides”, en Domínguez, N. et alii (eds.), Criaturas y saberes de lo monstruoso II, Buenos Aires, IIEGE/FFyL-UBA, (en prensa).

Segal, C. (1997) Dionysiac Poetics and Euripides'Bacchae, Princeton, University Press.

Segal, C. (1994), "Female Mourning and Dionysiac Lament in Euripides' Bachae", en Bierl, A. \& Möllendorff, P., Orchestra: Drama Mythos Bühne (Festschrift for Helmut Flashar), Stuttgart, 12-18.

Seisdedos, A. (1985), "Significación y desarrollo de las metáforas de animales en Eurípides”, Helmántica 36, 277-293.

Taplin, O. (2005 [1978]), Greek Tragedy in Action, Londres, Routledge.

Thumiger, C. (2007) Hidden Paths. Notions of Self, Tragic Characterization and Euripides' Bacchae, Londres: Institute of Classical Studies.

Wiles, D. (2007) Mask and Performance in Greek Tragedy from Ancient Festival to Modern Experimentation, Cambridge, University Press.

Wiles, D. (1999), Tragedy in Athens. Performance space and theatrical meaning, Cambridge, University Press.

Zeitlin, F. I. (1996), Playing the other. Gender and Society in Classical Greek Literature, Chicago \&London, The University of Chicago Press. 